\title{
Apontamentos para uma filosofia da comunicação em E. Husserl: a questão da intersubjetividade em sua fenomenologia transcendental ${ }^{1}$
}

\author{
Eli Borges Junior \\ https://orcid.org/0000-0002-0937-4741 \\ I - Universidade de São Paulo. \\ São Paulo (SP). Brasil.
}

Resumo: Em sua vasta obra intelectual, Edmund Husserl toca em arestas importantes que nos fazem pensar - ou mesmo repensar - estratos básicos tanto do próprio conceito como dos modos de operação daquilo que compreendemos por "comunicação". Como pensar esse termo em sua dimensão mais fundamental, aquela humana? O que nos permite atestar que "nos" comunicamos, que há aí um "eu" e um "outro"? Ou, em outros termos, como se daria uma das condições primeiras do ato comunicativo, a saber, a constituição dessa "intersubjetividade"? A fertilidade teórica com que Husserl trata questões como essas nos incita, neste artigo, a jogar luz sobre alguns de seus escritos como um terreno fecundo para o campo da filosofia da comunicação.

Palavras-chave: intersubjetividade; comunicação humana; alteridade.

Abstract: Notes for a philosophy of communication in E. Husserl: the question of intersubjectivity in its transcendental phenomenology In his vast intellectual work, Edmund Husserl touches on important edges 
that make us think - or even rethink - basic strata of the concept and modes of operation of what we understand by "communication". How to think of this word in its most fundamental dimension, that human one? What does allow us to attest that we "communicate", that there is a "me" and an "other"? Or, in other words, how would the fundamentals of communicative act operate, namely, the constitution of this "intersubjectivity"? The fertility with which Husserl problematizes questions like these makes some of his writings a fruitful ground for the philosophy of communication.

Keywords: intersubjectivity; human communication; otherness.

\section{Introdução}

A obra teórica de Edmund Husserl é desafiadora não só ao problematizar a ciência e a filosofia ocidentais, mas também por esmiuçar, com o rigor que Ihe é próprio, os modos de operação de processos como a socialidade, a linguagem e a comunicação. Não por acaso, seu legado ressoaria pelo século XX nos pensamentos de autores como M. Heidegger, M. Merleau-Ponty, H. G. Gadamer e J. Habermas. Com um trabalho de filigrana, Husserl parece nos oferecer importantes chaves para uma compreensão mais aprofundada daquilo que poderíamos apontar talvez como a pedra fundamental do processo comunicativo humano: a questão da intersubjetividade. Nesse sentido, este artigo se propõe a identificar em sua obra elementos férteis para o campo da filosofia da comunicação². Ora, como poderíamos descrever os estratos mais básicos da operação comunicativa, ou seja, como se daria a instauração da diferença entre um "eu" e um "outro", que parece ser fundamento desse processo?

Husserl ajuda-nos a deslindar esse dilema primordial do estabelecimento de um "outro", sem, no entanto, almejar levá-lo à exaustão. É o que faz ao se debruçar sobre a questão da intersubjetividade em uma de suas obras basilares, suas Meditações cartesianas (HUSSERL, 2013; ver também HUSSERL, 2011). Como tal questão se enovela de modo não pouco complexo nessa obra, daremos destaque à maneira como Husserl opera propriamente essa passagem entre dois níveis, a saber: o de um autorreconhecimento como sujeito que percebe e o da atestação de um "outro", o qual se constitui e se põe em exterioridade a esse mesmo sujeito.

A discussão que aqui faremos será, em grande medida, embalada pela perspectiva de Pedro M. S. Alves (2009, p. 8), professor da Universidade de Lisboa 
que tem dedicado esforços no sentido de pensar uma "futura teoria fenomenológica do fenômeno comunicativo", amparada fortemente na filosofia de Husserl ${ }^{3}$. A rigor, cumpre asseverar que, no universo da obra do filósofo alemão, não há propriamente a circunscrição de uma específica "filosofia" ou de uma "teoria" da comunicação, embora possamos extrair de tal universo relevantes aspectos a fim de pensar a comunicação em suas instâncias primordiais, como operação fundamental que, em Husserl, é chave de instauração da socialidade.

O objetivo deste texto, portanto, não atravessa a tarefa de buscar fazer de Husserl um autor do "campo da comunicação" par excellence. Pretende-se, antes disso, jogar luz sobre a questão da intersubjetividade como operação fundamental daquilo que o filósofo descreveria como comunicação, cujo elemento fundante se dá sempre "no quadro de um mundo comum" (ALVES, 2009, p. 41). O ato comunicativo aparece aqui, portanto, como processo humano e social, como aquilo que, para além de qualquer dispositivo ou media ou da "transmissão" de mensagens, caracteriza algo mesmo anterior, ou seja, nosso "agir em comum" (SODRÉ, 2014, p. 9-11).

Por isso, entre uma "teoria" e uma "filosofia" da comunicação, optaremos pela segunda alternativa, já que abordaremos a comunicação como um "fenômeno" (HUSSERL, 2013, p. 133; ALVES, 2009, p. 36-38), célula instauradora de um processo social, aqui descrito a partir da fenomenologia transcendental de Husserl e de sua temática da intersubjetividade.

Será a partir dessa temática que o filósofo construirá toda uma trajetória do conhecimento ${ }^{4}$, ora sob contornos predominantemente fenomenológicos, ora em raízes marcadamente ontológicas, a qual o levará a reflexões justamente sobre questões de natureza universal, como a comunicação e a linguagem. Como forma de explorar essa dimensão universal do tema da intersubjetividade, pretendo perpassar brevemente certas situações excepcionais, as quais parecem, já em um mínimo sobrevoo, apresentar pontos de interrogação às próprias reflexões do filósofo.

A discussão empreendida por Husserl nesse sentido inscreve-se no plano de fundamentação do transcendental, campo esse que funcionará como

3 Alves, vale destacar, inscrevê-la-ia num espectro possível de "filosofias da comunicação" (SANTOS; ALVES; SERRA, 2011).

4 Husserl $(2004 ;$ 2013; 1994) tem pretensões grandiosas e o apelo cartesiano de suas Meditações sobrevirá muito além do título de sua obra: orienta-se, com efeito, por um projeto de uma ciência universal cujas bases estariam fundamentadas em um rigoroso método capaz de conduzi-la ao "saber autêntico", tendo a filosofia como ponto de partida. 
terreno seguro no qual e do qual partiria toda a operação de atribuição de sentido à experiência no mundo. A fim de realizar propriamente a passagem do "eu" ao "outro", Husserl percorrerá um caminho pedregoso, e que aqui procuraremos expor de forma breve, abordando, fundamentalmente, as quatro primeiras de suas cinco Meditações.

\section{Do "ser" para o "aparecer": o senso comum e o mundo transcendental}

Visando à fundamentação de sua filosofia transcendental e preparando o terreno para essa tal passagem, Husserl empreende dois procedimentos filosóficos que buscam, em última medida, trazer à tona as evidências apodíticas. É a partir dessas últimas que se terá acesso ao território das essências, dimensão primeira da consciência e de todas as operações dela resultantes ${ }^{5}$. Por meio de um procedimento de redução, o qual denomina epoché (do grego غ́noxń = suspensão) e que se dará em duas etapas, Husserl empreende, movido pelas Críticas de Kant, um esforço de acesso ao mundo que intende se desfazer da ideia de conhecimento das coisas em si - o que Husserl relacionaria à noção de experiência natural - , mas que se concentraria sobre nossas condições subjetivas a priori de conhecimento da realidade.

Nesse primeiro procedimento, portanto, o filósofo busca, já na meditação primeira, "colocar entre parênteses" a "validade de ser do mundo objetivo" (HUSSERL, 2013, p. 63), ou seja, a própria realidade tal como a conceberíamos em uma atitude natural ${ }^{6}$. Essa primeira redução, a chamada غ̇ंกoxń7 fenomenológica, será assim responsável por suspender os grandes domínios da cultura, da socialidade e do fenômeno da comunicação propriamente dito - os quais viriam a constituir alguns de seus importantes temas de estudo, embora em uma filosofia muito mais ontológica do que par excellence fenomenológica.

Ao suspender a validade ontológica do mundo, Husserl pretende se centrar apenas sobre aquilo que "aparece" como experiência do sujeito:

5 O retorno ao "ego filosofante", propriamente o ego cogito, será, destarte, princípio que buscará se eximir, assim como a via cartesiana, de qualquer resquício de dúvida sobre o que se conhece, favorecendo o despontamento de uma "evidência apodítica e em si primeira" (HUSSERL, 2013, p. 52), algo indiscutível, grande assegurador dessa autenticidade.

6 Ou, segundo nos esclarece André Dartigues (1992, p. 20), "como existindo em si, independentemente de todo ato de consciência".

7 Seguindo a tradução do professor Pedro M. S. Alves e a própria versão francesa das Meditações de Husserl (1953), optamos aqui pela referência ao termo epoché em sua grafia original do grego (غ̇ंกoxń). 
desconsidera, pois, todas as possíveis definições relacionadas a essa experiência e que estejam propriamente fora dela. O que nos sobra, assim, é um "eu pensante" cujo pensado está imediatamente relacionado à sua própria experiência: seu mundo é o mundo que lhe aparece como fenômeno. Ao mesmo tempo, embora a redução nos legue um "eu pensante", temos disso uma consequência inalienável: na medida em que é pensante, esse eu sempre pensa algo e, portanto, nunca se encontra, por sua vez, isolado. Da redução fenomenológica, precisamente, resta não apenas esse "eu penso", mas também "seu objeto pensamento", não somente um ego cogito, mas um ego cogito cogitatum, como nos lembra Dartigues (1992, p. 22, itálicos do autor).

E aqui nos deparamos, assim, com uma circunstância que, em última medida, remete à própria constituição da intersubjetividade em Husserl. Seguindo a via cartesiana das Meditações, Husserl almeja chegar ao saber autêntico por meio de um método capaz de assegurar toda a sua indubitabilidade a partir da negação das prenoções sobre o mundo e ancorando-se apenas no que o próprio sujeito, como sujeito pensante, pode atestar. Porém, logo depois da redução fenomenológica, Husserl (2013, p. 44) se depara com o primeiro grande "extravio sedutor" deixado por Descartes: ao suspender a validade do mundo a partir da dúvida metódica, o filósofo francês já trataria esse "eu pensante" residual como substância pura e independente de qualquer outra ideia, até mesmo de ideias sobre o que é pensado. Para Husserl, ao pensar, a consciência jamais prescinde de um objeto de pensamento: essa sempre pensa algo, ou está "para" algo. É nessa medida que a consciência é sempre governada por uma intencionalidade (ver também HUSSERL, 2003; BENOIST, 2001), que a projeta, no limite, sempre para além de si mesma.

Por isso, em Husserl, embora possamos chegar a um estado puro do eu tarefa que o filósofo se põe - , nunca poderemos eximir a consciência de sua própria condição de "estar para algo". Qualquer um de seus atos - como a percepção, a imaginação e a memória - serão inexoravelmente operações realizadas sob a sua intencionalidade e, portanto, em relação a um objeto. Isso também abrirá espaço para uma concepção outra no que diz respeito à relação sujeito-objeto na investigação científica.

É forçoso, no entanto, realizar uma distinção entre o "eu puro", aquele ao qual Descartes pensava ter chegado já na suspensão do mundo extenso, e o eu psicológico. Opera-se, assim, um segundo procedimento de redução, uma segunda غ́noХń, agora mais refinada e que procura reduzir o domínio do 
subjetivo ao que Husserl chama de esfera primordial, o domínio do próprio, campo do qual acredita o filósofo poder extrair as essências da consciência e de todas as ideias por ela concebidas. Esse procedimento está diretamente relacionado a uma suspensão de qualquer resquício de subjetividade alheia, etapa necessária à garantia de um eu puro, com vistas, adiante, à universalidade mesma do conhecimento científico. Desse campo fenomenológico, Husserl então assinala:

Enquanto assumo a atitude transcendental, procuro, primeiro que tudo, delimitar o próprio-a-mim no interior do meu campo de experiência transcendental. Ele é, di-lo-ei em primeiro lugar, o não alheio. Começo, assim, por libertar abstrativamente este horizonte de experiência de tudo o que me é, em geral, alheio (HUSSERL, 2013, p. 133).

Nessa esfera residem as origens primeiras de todos os sentidos, as quais poderiam ser acessadas, embora ainda pela intuição, sem qualquer referência ao "alheio", remetendo apenas à intencionalidade do eu, agora puro. Será esse ego transcendental o responsável, como afirmará o filósofo, pelo "retorno às coisas mesmas", operação que resguardará toda a autenticidade que se esperaria de uma boa e positiva ciência.

Husserl alcança aqui, portanto, um importante ponto de inflexão de sua empreitada: esse retorno chega a seu nível mais fundamental, o nível das essências da consciência e de suas ideias, de seus atos em sua intencionalidade. É o momento, pois, de realizar o percurso contrário, ou seja, aquele do conhecimento objetivo a partir do próprio ego transcendental, curso esse do qual surgirá nosso ponto fulcral de estudo, a intersubjetividade com vistas à comunicação.

\section{Primeiro passo: do Leib ao Körper e o autorreconhecimento}

Guardada a miríade de outros importantes elementos das Meditações de Husserl, faremos aqui um salto operativo, agora com o objetivo de chegar ao ponto nevrálgico de nossa problemática. Ora, nesse percurso inverso, com vistas ao conhecimento objetivo, como Husserl opera então essa passagem de um eu puro, transcendental - reduzido até das subjetividades alheias - , para o "outro"? Como Husserl articula essa operação, responsável pela instauração da intersubjetividade, sem que caiamos em dois labirintos igualmente insolúveis: sua pressuposição como algo já dado (solução 
quase mágica para nossos problemas) ou o também, ou mais, problemático caminho de considerá-la como uma produção particular desse "eu puro" (recaindo, em certa medida, naquele referido "extravio sedutor" cartesiano)?

De todo modo, para chegar ao "outro", é mister que antes Husserl inicie uma operação de objetificação do mundo, o que começará pelo próprio corpo. 0 corpo será, pois, a primeira instância a partir da qual o filósofo empreenderá um caminho rumo à alteridade. Mas como organiza essa rota? É necessário, antes, demarcar uma diferença fundamental entre Leib, corpo vivo, unidade psicofísica, e Körper, corpo material, físico ${ }^{8}$. Ainda no definidor $\S 44$, será o reconhecimento do próprio Leib, a partir do ego transcendental, o ponto de partida para o reconhecimento das demais instâncias rumo ao "outro". Reconheço-me como subjetividade, como um corpo pensante e do qual atribuo sentido ao mundo a partir de minha consciência, que faz parte desse corpo. Ao mesmo tempo que sou um eu que pensa e que tem todas essas capacidades dadas por essa mesma consciência, até mesmo essa que me permite chegar a um eu reduzido - do qual abstraio o que lhe é alheio - , sou também um composto físico, do qual tenho ciência justamente a partir dessa minha ação consciente.

Ora, de meu Leib, meu soma psicofísico, tenho próprias condições de objetivar a mim mesmo a partir do reconhecimento de minha condição carnal, de meu Körper: sou, além de subjetividade, objeto, que percebo imediatamente graças a um ato de minha consciência, sentido intuído a partir de meu eu transcendental e que, portanto, assegura-me a certeza dessa percepção. Este é meu corpo e não um corpo alheio. A partir de meu Leib tenho meu primeiro objeto no mundo: meu corpo como Körper, composto carnal. A essa operação Husserl (2013, p. 137) dará o nome de autoapercepção objetivante ou mundanizante .

É importante notar que, não obstante seja objetivado por minha consciência, meu Körper não deixa de ser um domínio de minha esfera própria, de meu campo fenomenológico transcendental resultante da segunda غ̇ंoxń. Assim, a percepção de meu Körper, corpo material, coisal, dá-se em um domínio que é, ao mesmo tempo, transcendente e imanente: transcendente, porque em certo modo já se objetifica, e imanente na medida em que parte da esfera própria e nela, ainda, se constitui.

8 Na tradução do professor Pedro Alves, Leib é vertido como "soma", seguindo, como ressalta, sugestões de outras obras em que Husserl aproximaria os dois termos. Körper, por sua vez, torna-se "corpo" na tradução portuguesa. Optamos aqui por conservar os termos originais da tradução. 
Husserl prepara, assim, os fundamentos para o acesso ao "outro". A percepção de meu "corpo coisa", como nos sugere, será então o cais de partida desse trajeto. Mas a viagem talvez não seja tão confortável quanto parece ter sido até aqui, razão pela qual justamente se apresenta como nó górdio central deste nosso breve trabalho.

\section{Segundo passo: a "apercepção analógica" e o acesso ao "outro"}

Para explicitar propriamente a passagem do "eu" ao "outro" nas Meditações de Husserl, optamos por nos debruçar agora sobre os parágrafos 49, 50 e 51 , com destaque para o $\$ 50$, no qual se articula especificamente o acesso ao outro. No § 49, o filósofo, como deixará claro ao final do trecho, traz-nos uma "antevisão" do próprio percurso não apenas de constituição da intersubjetividade como também do acesso a uma "natureza objetiva" e a um "mundo objetivo em geral", estágios posteriores, dos quais não trataremos, no entanto, aqui em nossa reflexão.

Husserl chamará de "mundo primordial" o que, como nos lembra Natalie Depraz (2008, p. 180), fora denominado "mônada" na quarta meditação e "esfera própria" no § 44. A mudança de termos talvez torne um pouco menos turvo o movimento realizado pelo filósofo no início do § 49, quando parece preparar o terreno para a chegada do "alheio" e, mais, para o estabelecimento mesmo de uma noção de "comunidade", dada pela posterior reunião desses vários sujeitos outros com suas subjetividades próprias, "mônadas" que são. A mudança de termos, segundo Depraz (2008), poderia ser referida a uma "tentativa descritiva menos formal e menos polarizada pela qual se anuncia a noção de ego" (DEPRAZ, 2008, p. 180). "Mundo primordial" aí, escreve, abre-nos a uma noção de alteridade que "mônada" ou "carne"9 não dariam conta de aportar: trata-se de uma forma conceitual mais adequada encontrada por Husserl para "oferecer uma zona experiencial de indiferenciação originária, que permite a subsequente distinção entre o Eu e o outro Eu enquanto primeiro não Eu" (DEPRAZ apud LAVIGNE, 2008, p. 180).

Não seria por acaso, portanto, o adjetivo "mundanizante" agregado por Husserl à anterior "apercepção" do Körper. A percepção de meu corpo material é minha própria objetivação como sujeito, sujeito esse inscrito já em um

9 Como faz Husserl em seus manuscritos sobre a intersubjetividade, conforme nos diz Depraz (do francês, chair). 
mundo, mundo a mim primordial; “mundanizado”, embora ainda no domínio do próprio, vislumbro um externo na medida em que devo colocar-me junto a outros egos, a outros homens psicofísicos que também se apercebem, numa "comunalização" a partir da qual reconheço e reconhecem - sublinhe-se esse "nós" - "um mesmo e único mundo" (HUSSERL, 2013, p. 145). Dessa intersubjetividade irromperá, pois, a própria objetividade do mundo.

Recuemos, no entanto, um pouco nesse movimento e situemo-nos no centro da questão que aqui mais nos interessa: o que o filósofo denominará, já no título do § 50, "apercepção analógica". Husserl (2013, p. 147, grifos no original) necessita organizar, antes mesmo da passagem de um "eu" ao "outro", a passagem de um próprio (eigen) à "experiência do alheio" (fremd), uma vez que, como pontua, "o outro ainda não chegou a revestir o sentido homem". Chegamos, assim, a um momento crucial na medida em que tal movimento parece representar o primeiro descolamento em relação à esfera própria; afinal, mesmo tendo objetivado meu Körper por meio de meu Leib ${ }^{10}$, o reconhecimento dessa materialidade coisal do corpo se inscreve ainda em um domínio transcendente imanente do próprio. Essa distinção entre "próprio" e "alheio" é fundamental na medida em que devo garantir a mim mesmo que o que tomo como experiência do alheio não se refere, de modo algum, à minha essência própria, pois "se o que é próprio e essencial ao outro me estivesse disponível de um modo direto, então o outro seria apenas um momento da minha essência própria e, em conclusão, ele e eu seríamos o mesmo" (HUSSERL, 2013, p. 147).

Se até aqui a intencionalidade operaria sempre com vistas a alcançar algo ainda circunscrito à esfera do próprio (como o reconhecimento de meu Körper), parece haver, com a experiência do alheio, uma modificação da própria intencionalidade, pois, ao me colocar diante do alheio, não tenho mais sobre ele todas as possibilidades de percepção que teria dentro de minha própria esfera. É por isso que Husserl nos fala em uma "mediatez da intencionalidade", uma "intencionalidade mediata", a qual, na impossibilidade de uma percepção completa, torna "copresente", "apresenta" aquilo diante do que me coloco. Essa copresentação, ou "apresentação"11 pode se converter em presentação na medida em que percebo diretamente aquilo que me é ocultado.

10 Pela operação da "autoapercepção mundanizante", no § 45 de suas Meditações.

11 "Apresentação" que não pode ser entendida em seu sentido usual e aqui demarca uma diferença mesmo opositiva em relação ao termo "presentação". Por isso, grafaremos com aspas o termo e seus correlatos. 
Se me coloco, por exemplo, diante de um cubo, não posso, num primeiro olhar e limitado por minha visão tridimensional, investir-me de absoluta certeza de tratar-se mesmo de um cubo. Afinal, as faces que se me ocultam poderiam muito bem revelar inimagináveis segredos: uma superfície côncava, uma sobressalência piramidal ou mesmo um vazio, a abertura de um oco. Mas a mim é possível recorrer à simples tarefa de pegá-lo à mão e verificar a sua perspectiva que antes a mim se ocultava, ou mesmo, posso, sem mover a figura, mover a mim mesmo e percorrer o lado do cubo a que antes não tinha acesso.

É possível, portanto, tornar presente a face que antes se copresentava a mim. Mas caso absolutamente distinto é quando me refiro ao outro. Por mais que conheça seu corpo, nos seus mais secretos recônditos, por mais que o disseque em operação de filigrana, há algo de si a que jamais terei acesso como presentação, como percepção minha em sentido próprio: a sua esfera própria, seu "alter-ego". Esse será sempre o enigma dos enigmas, tarefa impossível, mesmo filosoficamente, pois só poderia experimentá-lo sendo propriamente o outro e, portanto, já deixando de ser eu mesmo.

O que, no entanto, ao me colocar diante de um alheio que se converterá em homem, impede-me de tomá-lo como simples objeto? Como constato ser aquele também um Körper, algo semelhante ao meu Körper? Mais: o que me impele a crer que há ali também um Leib que governa o Körper que se me presenta, e, em última instância, que há ali um outro de mim?

Segundo Husserl, o que me leva a reconhecer o outro como um corpo vivo e não apenas um corpo carne e, portanto, como semelhante a mim, é operado por meio de uma "transferência aperceptiva" de sentido do meu Leib ao corpo alheio. Circunscrito a meu mundo primordial, o que tenho acesso a partir de meu campo perceptivo é, no limite, meu Leib e meu Körper e, ainda que eu reconheça o Körper alheio como Körper de um outro, jamais terei plena certeza de que se trata realmente de um outro em toda a sua autenticidade. Isso porque, como pontuamos acima, nunca poderei experimentá-lo como um Leib enquanto alheio a mim. No entanto, não sou posto a esmo, mas, quando reconheço aquele Körper como Körper alheio e como semelhante ao meu, acabo, analogicamente, por transferir as mesmas propriedades que tenho a ele: se me reconheço como um Leib dotado de um Körper e se vejo no corpo alheio traços semelhantes ao meu, logo, transfiro a ele o mesmo sentido que dou ao meu, ainda que ele sempre esteja fora de minha esfera própria (ou então seria meu próprio corpo e não um outro). 
O próprio Husserl (2013, p. 149), no entanto, já nos anunciaria um ônus a ser considerado nesse percurso: por mais que reconheça semelhanças entre meu Körper e o Körper alheio e, por mais que, analogicamente, chegue à consideração de tratar-se de um outro, com seu Leib, nunca se contará com uma "comprovação efetivamente direta", uma "comprovação através de uma percepção em sentido próprio". Seguindo Husserl, nunca poderei, pois, perceber direta e integralmente os "predicados da somaticidade" alheia. Por isso a importância dessa "apreensão analogizante".

Somos, então, tomados por duas problemáticas praticamente inescapáveis. A primeira: como se dá o reconhecimento dessas semelhanças e, mais especificamente, o que me faz relacionar dados que não são idênticos entre si? Por que vejo uma relação entre eles? E a segunda, consequência da primeira: essa correlação de egos, qual seja, o reconhecimento do outro como outro, será sempre necessária?

Em resposta a essa primeira problemática, Husserl nos introduz o processo do "emparelhamento" (Paarung), uma espécie de síntese passiva que associa dados semelhantes de meu e do outro "modos de aparecer corporais" (DEPRAZ, 2008, p. 186). Husserl (2013, p. 150) associa o fenômeno do emparelhamento a uma "protoforma" da "síntese passiva" que designara, em momentos anteriores de sua obra, como "associação", em "oposição à síntese passiva de identificação". Ao serem colocados lado a lado, em regime de normalidade, dois Körpers não se fiam por uma identidade: são sempre diferentes entre si, seja em suas dimensões, sua tonalidade e textura da pele, sua posição e a posição de seus membros, seus cabelos, sua expressão facial, suas digitais - poderíamos aqui recorrer a um sem número de elementos -, condição que, em última instância, impediria uma síntese com dados idênticos. Os dados são, sim, distintos entre si, embora possamos associá-los, independentemente de nossa vontade, pareando-os e relacionando-os, ao fim, como "semelhantes"12. Há, aí, pois, como ressalta Depraz (2008, p. 186), uma "passividade" como primeiro componente da experiência analogizante, o que torna o emparelhamento um fenômeno que "se produz mesmo aquém de toda atividade perceptiva (visual, tátil, auditiva) de 'apreensão' pela observação e identificação do objeto" (DEPRAZ, 2008, p.186).

Há, portanto, aí, um reconhecimento da não identidade entre os elementos de um e de outro Körper, o que, em última medida, acaba anunciando, nessa 
própria lacuna, o que Depraz (2008) apontará como uma "possível experiência de liberdade" de um em relação ao outro. Mas, ao mesmo tempo, não seria esse espaço uma espécie de clivagem no sistemático caminho filosófico até agora construído por Husserl? É o que nos encaminha à segunda problemática há pouco aqui apresentada.

Ora, essa espessidão entre um e outro dado associado, em última instância isenta de plena segurança, é a mesma espessidão que retoma a indagação, apesar de todo o esforço em esclarecê-la: o que me faz pôr em semelhança? No limite, que critérios determinam que duas coisas (como esses corpos de que falamos) sejam aproximadas sem que guardem uma relação de identidade? Que elas "se pareçam" é uma resposta superficial, que não resolve o problema, mas o recoloca na medida em que não posso, em última instância, apontar uma correspondência necessária, forçosamente entre uma coisa e outra. Ao mesmo tempo, fato é que realizamos esse tipo de operação, seja ou não nos moldes da síntese passiva de Husserl.

De qualquer forma, parece haver justamente no momento de instauração de uma intersubjetividade, de passagem do "eu" ao "outro", um salto um tanto quanto desconfortável, ao menos diante da vista daqueles habituados ao rigor primoroso de suas Meditações até aqui. Em comentário às consequências da tese da Paarung de Husserl, Pedro M. S. Alves (2009) refere-se a uma certa precariedade dos fundamentos dessa constituição da intersubjetividade a partir de um processo sintético em que a transferência de sentido se dá por analogia. Segundo Alves (2009, p. 94), essa base se assentaria "apenas na percepção de um corpo e na transposição analógica pela qual esse corpo devém Leib e esse Leib se volve no lugar de expressão de uma vida psíquica. Nenhum outro processo é requerido", embora o próprio professor reconheça também uma vantagem dessa mesma tese, dada pela "universalidade do autorreconhecimento dos humanos".

Pois é justamente desse aspecto que parece emergir um questionamento que, no mínimo, soa-nos um tanto quanto incômodo e não deixa de evocar o tal salto a que nos referimos acima. Falar aqui nessa "universalidade" entre os humanos - mesmo fora dos "processos de socialização que os repartem em unidades histórica e culturalmente indiferenciadas e até mesmo incomunicáveis" (ALVES, 2009, p. 94) - parece significar que todos eles seriam capazes, mesmo excluídos de todas essas circunstâncias, de reconhecer o outro como semelhante, uma quase natureza humana que se conectaria quando dois dos seus se colocassem em "apresentação". 
Pois exemplos como o de Kaspar Hauser ${ }^{13}$, ou do menino Peter, de Hanover ${ }^{14}$, oferecem-nos, no mínimo, importantes arestas para discussão. Eles nos desafiam a pensar em que medida Kaspar ou Peter de fato reconheceram como seus semelhantes os primeiros humanos com quem tiveram contato. Ao ser deixado em praça pública na cidade alemã de Nuremberg, Kaspar, excluído desse arcabouço cultural, histórico e mesmo linguístico a que se refere o professor Pedro Alves, teria mesmo condições de se autorreconhecer como um membro da comunidade humana ao encarar aquele com quem primeiramente trocaria olhares?

O exercício reflexivo é extensível ao caso de Peter, de Hanover: em que medida teria o menino reconhecido o primeiro humano com quem teve contato muito mais como um semelhante de si do que propriamente os lobos com que parece ter convivido até a idade em que seria encontrado? Seus comportamentos, muito mais próximos aos de uma alcateia do que propriamente aos de uma comunidade humana, não poderiam sugerir algo diverso? Isso se torna ainda mais instigante ao pensarmos que passaria toda a vida sem dizer mais do que três curtas palavras. É possível, pois, sustentar tal "universalidade"?

\section{Considerações finais}

Embora a questão acima nos faça pensar sobre a própria validade do percurso que Husserl constrói entre o "eu" e o "outro, ela aqui é trazida muito mais como tentativa reflexiva no sentido de reconhecer arestas e buscar apará-las, do que de sinalizar pontos de fragilidade capazes de fazer ruir

13 O jovem rapaz, que seria posteriormente chamado de Kaspar Hauser, aparecera certo dia de 1828 em uma das praças da cidade de Nuremberg (Alemanha), vestido com trajes da época e portando à mão uma breve carta. Kaspar não sabia caminhar nem articular qualquer palavra e, segundo tal carta, teria vivido em cativeiro até então, quando parecia contar com cerca de dezessete anos de idade. Seu caso é bastante emblemático sobretudo entre os linguistas, ao discutirem a relação entre a aquisição da linguagem e a constituição do pensamento (BLIKSTEIN, 2003). Para mais detalhes sobre a vida de Kaspar, vale conferir a biografia narrada por seu principal tutor, Paul Johann Anselm von Feuerbach (1833), além da obra muito bem organizada por Luc Meichler (2003), com trechos dos próprios manuscritos de Kaspar (que aprenderia a escrever anos depois de ser encontrado). Além disso, destaco também a célebre película dirigida por Werner Herzog (1974) e protagonizada por Bruno S.

14 Mais conhecido como "Peter, the Wild Boy", o menino despertou a atenção da cidade de Hanover (Alemanha), em 1724, ao ser encontrado sem qualquer vestimenta, com a pele escura e hábitos muito semelhantes aos de um animal selvagem. Sem articular um só vocábulo, diz-se que teria vivido na floresta até por volta de seus 12 anos, quando cruzaria o caminho do rei George I da Grã-Bretanha, durante uma caçada. Segundo relatos, Peter nunca se integrara completamente à sociedade da época, tendo chegado ao fim da vida sem pronunciar nada mais do que três palavras: "Pedro" e "Rei George" (ver DOUTHWAITE, 1997). 
o seu edifício lógico. E nessa direção sugere ir o próprio Husserl (2013, p. 152) ao reconhecer a impossibilidade de comprovação efetivamente direta do processo de transferência de sentido de meu Leib ao Leib alheio. Ele acaba por destacar essa mesma impossibilidade como aspecto determinante para uma transposição do eigen ao fremd: não poder perceber diretamente, como constituinte de meu mundo primordial, que aquilo que me aparece é conditio sine qua non para que tal corpo seja alçado à qualidade de alheio.

Dessa forma, esse salto de que falamos poderia, em certa medida, ser visto a partir de dois prismas diversos e que, apesar da contradição aparente, no fundo acabariam por constituir quase que o mesmo objetivo, qual seja, o próprio acesso a um "outro". Por um lado, poderíamos ver essa passagem ao Leib alheio como um salto cego, porque não completamente confirmável, em meio a um percurso perfeitamente arquitetado, salto arriscado que, na impossibilidade de garantias mais sólidas, parece não coadunar com toda a trajetória das Meditações até aqui. Abre-se, nesse sentido, uma perspectiva ao incerto, uma fenda em sua sistemática e precisa orquestração filosófica que procura, desde o princípio e a todo preço, esquivar-se de qualquer fresta de dubitabilidade.

Por outro lado, essa perspectiva que nos lança para fora de nosso mundo primordial é justamente o aspecto determinante para que possamos acessar algo diverso de nossa esfera própria. E aí, embora se trate de um processo não absolutamente confirmável, tal transferência de sentido não se fecha às possibilidades de uma certa confirmação - ainda que indireta - a partir dos comportamentos daquele considerado como "outro". É pelo que vai se presentando a mim, ao observar esses comportamentos, que renovo tal sentido, dilapido-o a partir desses novos aspectos que vão se revelando e que me servem como importantes indícios de que não estou sozinho no mundo. Mas, como deixa escapar Husserl, ainda que me comunique com aquele que concebo como "outro" e o reconheça como "semelhante", jamais terei a completa certeza disso: ao fim e ao cabo, posso mesmo estar rodeado não mais do que de perfeitos autômatos.

De todo modo, a questão da intersubjetividade, ou ainda o que aqui se descreve como o percurso do "eu" ao "outro", é em Husserl o ponto inicial de uma trajetória que nos conduziria da esfera do "próprio" ao domínio do social. A comunicação em Husserl residiria justamente nesse arco, sendo por isso, como sintetiza Alves (2009, p. 103), "o protofenômeno da socialização". 
Como complementa:

A evidência de um mundo comum será, justamente, o correlato ideal final do processo comunicativo, enquanto "ideia em sentido kantiano". Mais que um ponto de partida, a constituição intersubjectiva de um mundo comum e de uma comunidade intermonádica é, assim, a tarefa infinita do processo de comunicação (ALVES, 2009, p. 102).

Essa citação de Alves acaba por sintetizar aqui um percurso intrincado e, por isso mesmo, seria inviável, na ocasião de um artigo acadêmico, determo-nos sobre todo esse périplo filosófico que Husserl narraria - guardados os devidos pesos em que o tema se deslinda em cada ocasião - em várias de suas obras. Por isso, a fim de manter a diligência de uma leitura que procura explorar os meandros do texto do filósofo, dedicamo-nos aqui especificamente a esse primeiro percurso, dado até o estabelecimento de um "outro", percurso sem o qual, seguindo a filosofia de Husserl, não se poderia estabelecer alguma forma de comunicação.

Em outras palavras, o caminho que seguimos aqui sugere que talvez não seja mesmo possível conceber o fenômeno comunicativo prescindindo da discussão sobre os temas da subjetividade e da intersubjetividade ${ }^{15}$. Comunicar-se sobrevém de uma intencionalidade a encontrar-se com outra(s) intencionalidade(s) ${ }^{16}$, cada uma das quais, conquanto possam partilhar de um mundo comum, tem seu seio forjador justamente na esfera própria, que, portanto, não parece escapar mesmo do status de condição primeira do ato comunicativo.

Diante de todas essas considerações, reiteramos, pois, que aqui nossa tarefa não se perfez, de modo algum, como pretensão de oferecer um espectro fechado ou definitivo a partir do qual pudéssemos orientar uma reflexão sobre o tema da comunicação em Husserl. Nosso objetivo, procurando desdobrar esse tema, foi o de oferecer certos "apontamentos" a fim de pensá-lo como campo em que "eu" e "outro" se colocam em comum. Campo multifacetado como aquele da própria filosofia, a nos exigir sempre o exercício da dúvida e o reconhecimento de possíveis aporias. Afinal, essa é uma lição

15 Ainda que essa relação seja problemática, já que as questões específicas da intersubjetividade e da comunicação devem ser concebidas como dois temas que, a rigor, não se fundem nem se confundem (ver ALVES, 2009, p. 8-9).

16 Ainda que, é forçoso ressalvar, tal ato não possa ser reduzido somente a isso (ver ALVES, 2009, p. 102-103). 
que o próprio Husserl apresentaria em vida, como nos faz ver a breve nota de Marilena Chaui (2002, p. 176): “Husserl, poucos dias antes de sua morte, proferiu uma conferência na qual afirmava que sua obra - gigantesca estava equivocada e que iria recomeçá-la, pois havia, finalmente, compreendido o que deveria ser o objeto da filosofia".

Eli Borges Junior é doutor e mestre em Ciências da Comunicação pela ECA/USP; é bacharel em Comunicação Social pela mesma instituição e em Filosofia pela FFLCH/ USP. Foi bolsista de doutorado da FAPESP.

ridolfi.eli@gmail.com

\section{Referências}

ALVES, P. M. S. Intersubjetividade e comunicação: uma abordagem fenomenológica. Lisboa: Centro de Filosofia da Universidade de Lisboa, 2009.

BENOIST, J. Intentionalité et langage dans les Recherches logiques de Husserl. Paris: PUF, 2001.

BLIKSTEIN, I. Kaspar Hauser ou a fabricação da realidade. São Paulo: Cultrix, 2003.

CHAUI, M. S. Experiência do pensamento: ensaios sobre a obra de Merleau-Ponty. São Paulo: Martins Fontes, 2002.

DARTIGUES, A. O que é a fenomenologia? Trad. Maria José J. G. de Almeida. 3. ed. São Paulo: Moraes, 1992.

DOUTHWAITE, J. Homo ferus: between Monster and Model. Eighteenth-Century Life, Duke University Press, Durham, vol. 21, n. 2, mai. 1997, pp. 176-202.

FEUERBACH, P.J. A. Caspar Hauser: an account of an individual kept in a dungeon, separated from all communication with the world, from early childhood to about the age of seventeen. Trad. Henning Gottfried Linberg. Boston: Allen \& Ticknor, 1833.

HUSSERL, E. La crise des sciences européennes et la phénoménologie transcendantale. Trad. Gérard Granel. Paris: Gallimard, 2004 [1936].

Meditações Cartesianas e Conferências de Paris. Trad. Pedro M. S. Alves. Rio de Janeiro: Forense Universitária, 2013 [1950].

Méditations Cartésiennes. Trad. Gabrielle Peiffer e Emmanuel Levinas. Paris: J. Vrin, 1953 [1931].

Phénoménologie et anthropologie [1931]. In: HUSSERL, E. Notes sur Heidegger. Trad. e org. de Denise Souche-Dagues. Paris: Minuit, 1994. 
Recherches Logiques. Trad. Hubert Élie, Arion L. Kelkel e René Scherer. Paris: PUF, 2003 [1900]. 2 tomos.

Sur l'intersubjectivité. Trad. e org. de Nathalie Depraz. 2. ed. Paris: PUF, 2011 [1973]. 2 tomos.

DEPRAZ, N. Commentaire de la Cinquième Méditation (Deuxième partie: § 49-62). In: LAVIGNE, J-F. (Org.). Les Méditations Cartésiennes de Husserl. Paris: J. Vrin, 2008. p. 175-214.

MARCONDES FILHO, C. O princípio da razão durante: comunicação para os antigos, a fenomenologia e o bergsonismo. Nova Teoria da Comunicação III - Tomo I. São Paulo: Paulus, 2010.

MEICHLER, L. Écrits de et sur Kaspar Hauser. Trad. Jean Torrent. Paris: Christian Bourgois, 2003.

O Enigma de Kaspar Hauser (Jeder für sich und Gott gegen alle). Direção: Werner Herzog. Alemanha: 1974 (110 min).

SANTOS, J. M.; ALVES, P. M. S.; SERRA, J. P. (orgs.). Filosofias da Comunicação. Covilhã (Portugal): LabCom Books, 2011.

SODRÉ, M. A ciência do comum: notas para o método comunicacional. Petrópolis: Vozes, 2014.

Artigo recebido em 07/09/2020 e aprovado em 11/12/2020. 